\title{
Real Time Tele Medical Assistance Systems with Sensor Data Analysis Framework - Project Fast Care
}

\author{
Peter Kussmann ${ }^{1}$, Sabrina Hoppstock ${ }^{2}$, UHP Fischer-Hirchert*3 and Hochschule Harz ${ }^{4}$ \\ University of Applied Sciences Wernigerode, Germany
}

Received: June 06, 2018; Published: June 22, 2018

*Corresponding author: UHP Fischer Hirchert, University of Applied Sciences, Photonic Communications Lab, Friedrichstrasse 57-59, D-38855, Wernigerode, Germany

\section{Abstract}

The combination and fusion of technologies and procedures from Ambient Assisted Living (AAL), Human-Technology Interaction (MTI) and eHealth to target a real-time capable sensor data analysis-framework is the research focus of the fastcare-project. Measurement and observations by an adhoc-networked, real-time sensor infrastructure with the goal of creating an integrated situation picture for direct interaction with an actor infrastructure or for the generation of a future forecast - with a latency period of less than $10 \mathrm{~ms}$.

Keywords: AAL; MTI; eHealth; Tele-Reha; Mhealth; Tele Care; Care; Real Time; Vital Data; K.4.1 Public Policy Issues [Computer-Related Health Issues]; I.2.1 Applications and Expert Systems [Cartography]

\section{Introduction}

Assistance systems in Ambient Assisted Living and in medical care have to recognize relevant situations, that require fast assistive intervention. Former projects in this field like tecla [1-3] or PAUL [4] have been focused on the application of the new AAL-technologies in AAL test beds to get information about the acceptance level $[5,6]$ of the technologies and the different new applications for the patients. Additionally, business models [7] have been drafted to realize a successful AAL business area in future. The clinical established measurement technology for diagnostic, monitoring and risk stratification does not translate directly to the outpatient area (ambulant or domestically environment). The key challenge is, that many relevant situations are only noticeable, when various sensor modalities are merged such as for discrimination between pathological, emotional or stress induced increase of the heart rate.

This is only possible by the use of the combination of multiple different sensors. The same applies to the analysis of joint kinematics of everyday activities, which requires more and inertial sensors with higher accuracy. Sensor data analysis-frameworks are needed to analyze the conditions of real-time identification and subsequently provide a medical valid corresponding assistance.

\section{Principles}

The basis of a medical valid - integrated real-time picture of the situation is an ad hoc interconnected sensor infrastructure. Its latency period should be less than $10 \mathrm{~ms}$ to fulfill the boundaries of a haptive working network. Here, physiological, cognitive and kinematic information of a patient are captured with the help of intelli gent sensor data fusion. This information combined will provide an integrated picture of the patient's physical and mental situation. In this way, it should be ensured that the framework can be used for applications, in which feedback has to be embedded synchronically. This can be realized in visual, auditive, tactile or proprioceptive string of perception, such as in the field of support of motor function and kinematics for the rehabilitation and for active prosthetics and orthotics. This will form the basis for high-end assistive technologies. Fast care will create the technical requirements to protect humans from damage in their natural environment. The next generation of medical technology should be perceived as a non-contact, integrated system to support the user with technology that is reliable, preventive and easy to handle (Figure 1).

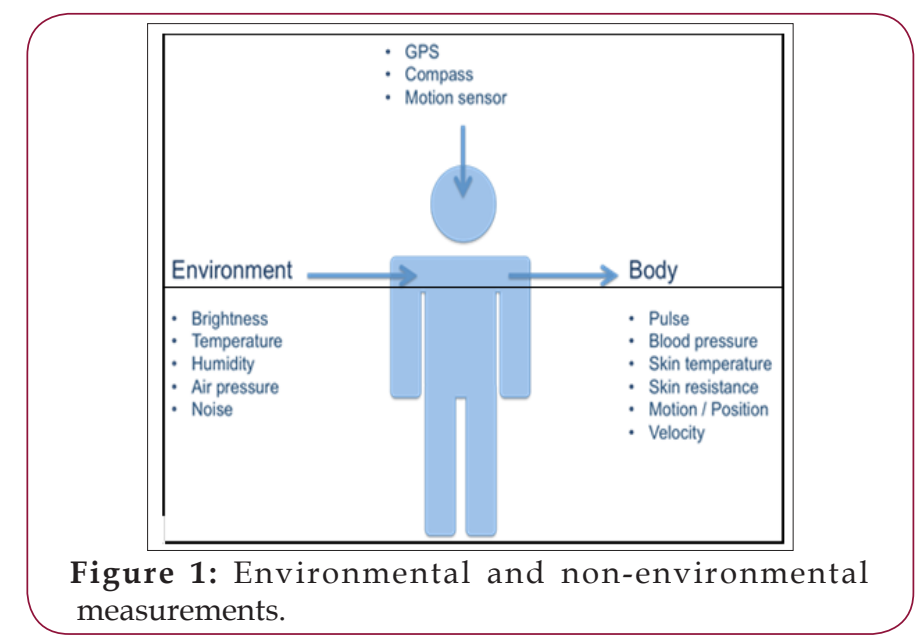




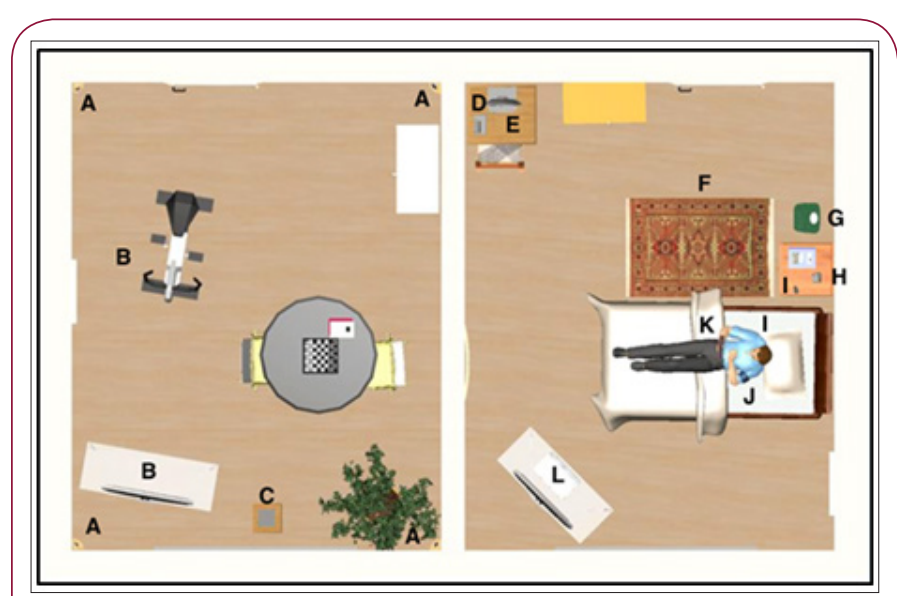

A: sensors on the walls: pulse, blood pressure, skin temperature, skin resistance, motion / position, velocity

B: eReha

C: real-time controller

D: telephone

E: touchscreen

F: sensefloor

G: scale with bluetooth

H: bluetooth modem

I: smart sleep system

J: blood pressure monitor

K: asina tablet

L: tv set with top box

Figure 2: MTI-Lab of the Harz University.

The challenge of a distributed, real-time medical sensor technology and signal processing is to be processed by means of sensor-based data processing and sensor hubs, optical sensors, hardware system optimisation, the development of distributed systems as well as by interface network sensors. The focus of the project is on the intelligent fusion of sensor and actuator data as well as the evaluation and delivery in real-time. In order to meet this objective, the following researches will take place in the MTI-Lab of the Harz University of Applied Sciences in Wernigerode (Figure 2):
a) Analysis of requirements
b) Data acquisition
c) Data analysis
d) Data fusion
e) Acceptance analysis
f) Situation detection and assistance in real-time

Rapid and intelligent sensors and actuators, an improvement of motion pattern recognition and intelligent algorithms for real-time network integration in three demonstrators of the MTI-Lab serve as solution approaches. Within the fast care project, a real-time network integration with demonstrators is to be carried out at the MTI-Lab of the Harz University. The various partial results of the project partners will be collected and integrated in the MTI-Lab.
The integration at the MTI-Lab will be performed with the focus on user friendliness and the interaction with him by means of a show flat. Figure 2 illustrates the planned structure of the MTI-Lab with various elements for a monitoring and evaluation of the measured values.

\section{Primary Approach to Research}

Approach to research are the ideas of measurements and observations on the one side - direct interaction or the generation of a future forecast on the other side. Today, there already exist similar procedures for other tasks. For example, strain here "weather observations", "weather measurements", as well as "weather forecasts" called. The system diagram of the research approach of the fast care framework is shown in the following figure see Figure 3).

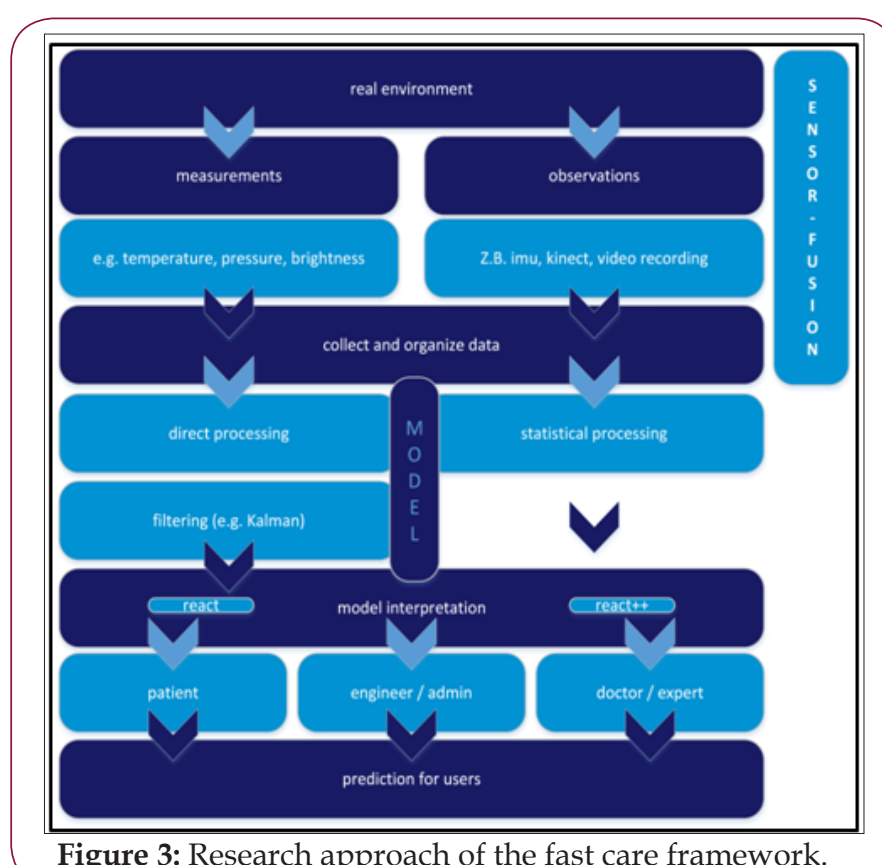

\section{System Concept}

The collaboration of eight project partners enables a successful project. Every partner takes part in a special way to meet the challenge of a distributed, real-time medical sensor technology and signal processing see Figure 4. The different focal points of the project partners are:

a. Bosch Sensortec GmbH: sensor-based data processing and sensor hubs

b. HarzOptics GmbH, Technical University Dresden: optical sensor technology, cardiopulmonary performance

c. University Rostock, Exelonix GmbH: the estimation of cognitive condition, hardware system optimisation and the development of distributed systems

d. Harz University of Applied Sciences: interface network sensor technology and analysis of acceptance

e. Ottobock GmbH \& Co. KG: application and development of intelligent orthopedic devices 
f. Otto-von-Guericke-University Magdeburg: the motion analysis for rehabilitation

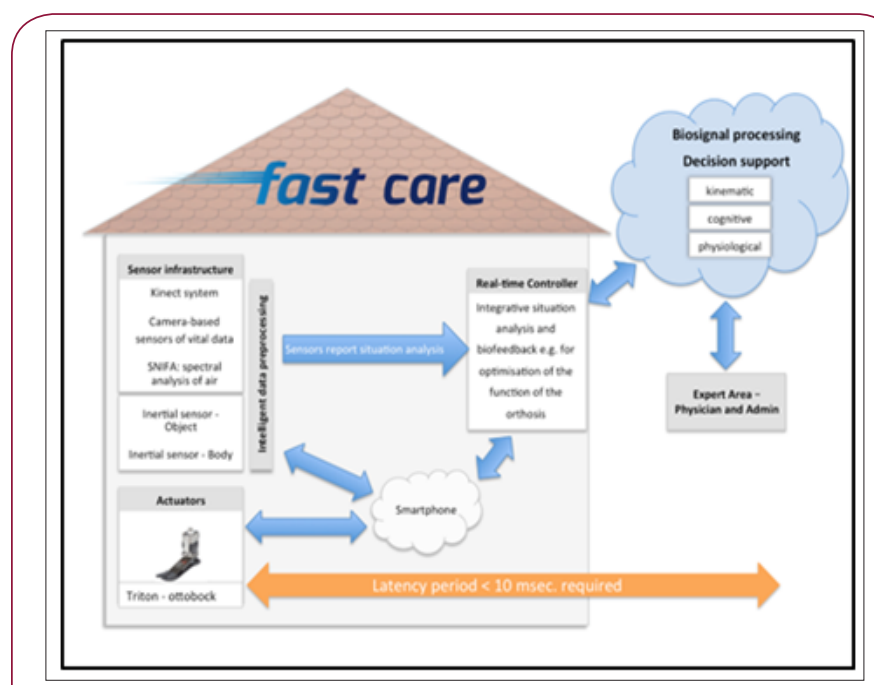

Figure 4: System concept of fast care.

The objective of a distributed, real-time medical sensor technology and signal processing is to get an evaluation of the patient's situation from the available data in real-time. The main application lies in the area of the application of orthopedic devices (prosthesis, orthosis: Otto bock). For example, the optimization process of the leg prosthesis`damping members and active foot positioning points shall be executed online. Currently, these parameters are performed offline and hand-made by orthopedic technicians with variable quality. This often leads to suboptimal adapted orthopedic devices, whose functionality and efficacy are correspondingly limited and therefore to an unsatisfactory rehabilitation outcome. Another project section describes the online execution of the estimation of cognitive condition (University Rostock), the motion analysis for rehabilitation (Otto-von-Guericke-University Magdeburg) and cardiopulmonary performance (Technical University Dresden, Harz Optics GmbH).

The fast care framework is the technical basis for the realization of the fast care project, which implements the fusion of heterogeneous sensors via heterogeneous networks. The basic idea of the fast care framework is to derive a condition from the past and the current states of the sensory data using the known physical rules. The fast care framework includes the following areas and interfaces see Figure 5:
a. Hardware
b. Sensors
c. Actuators
d. Real-time server connected to moving cloud
e. Networking

\section{f. Data analysis \\ g. Feedback and Intervention}

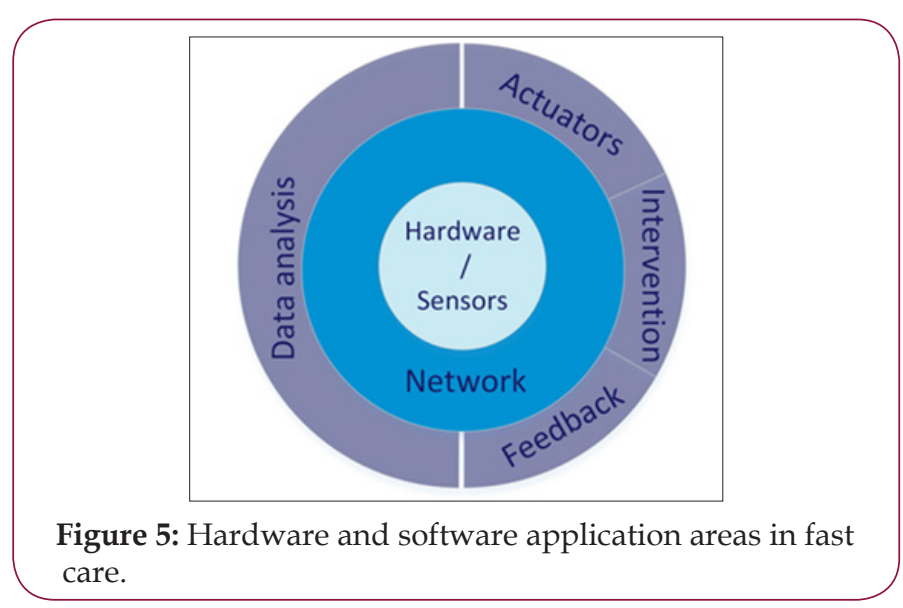

In addition to the technical development activities, an analysis of acceptance will be executed at the MTI-Lab of the Harz University. As a result of the project, fast care wants to develop feasible products and create the medical fundamentals for an interaction (feedback) in real time.

\section{Acknowledgment}

The project is supported by the German Federal Ministry of Education and Research in the program Zwanzig 20 - Partnerschaft für Innovation contact no. 03ZZ0519I. We thank all fast care project partners for their contributions to this work

\section{References}

1. UHP Fischer Hirchert (2014) Anwendung von technikgestützten Pflegeassistenzsystemen in der Harzregion. Gerontol und Geriatr. Kongress p. 1.

2. UHP Fischer Hirchert (2012) Technische Pflegeassistenzsysteme TECLA WZW in Fachtagung Gesundheitsregion Harz.

3. L Schelisch, TU Kaiserslautern (2014) Wer nutzt eigentlich PAUL ? Erfahrungen aus dem Praxiseinsatz Who makes use of PAUL ? Empirical Findings on User Experience".

4. S Meyer, H Mollenkopf (2011) Ambient Assisted Living (AAL): Komponenten, Projekte, Services. Eine Bestandsaufnahme.

5. A Kung, B Jean Bart (2010) Making AAL platforms a reality in Lecture Notes in Computer Science (including subseries. Lecture Notes in Artificial Intelligence and Lecture Notes in Bioinformatics) 6439: 187196.

6. UHP Fischer, K Rost, H Harz (2014) Businessmodell zur Applikation von AAL-Userportalen zur Verbesse- rung der sozialen Teilhabe älterer Menschen in der Harzregion Business model for the application of AALuser portals to improve the social participation of older people in the Harz. AAL-Kongress.

7. J Bauer, EHB Technologiezentrum (2014) optimierung der datenvisualisierung von aal-serviceplattformen durch usability-tests optimization of data visualization for aal service platforms through usability testing kurzfassung einleitung vorgehen. 
CC (i) This work is licensed under Creative Submission Link: https://biomedres.us/submit-manuscript.php

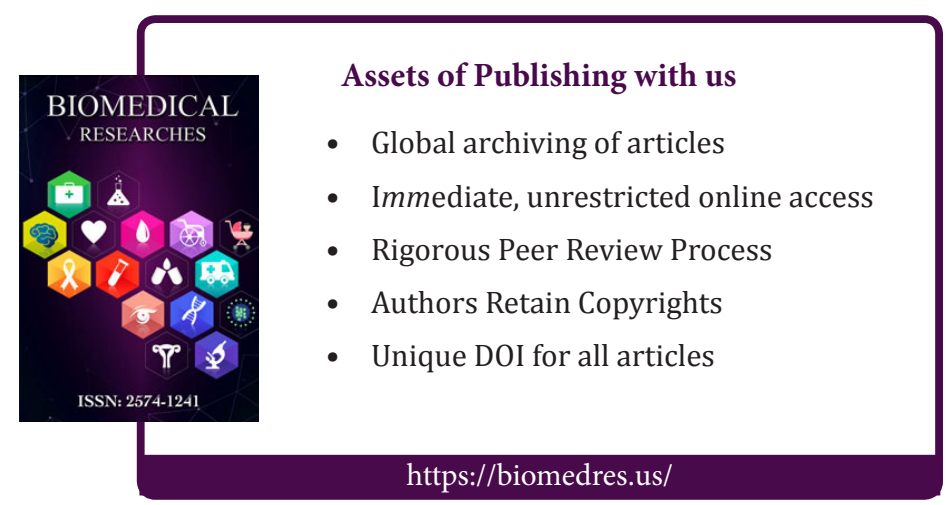

